\title{
SET-UP OF INTEGRATED SYSTEM FOR REAL-TIME DETECTION AND RECORDING OF MANY ENGINE PARAMETERS OF AGRICULTURAL MACHINES DURING DYNO TESTS
}

\author{
Marco Bietresato, Matteo Malavasi, Fabrizio Mazzetto \\ Libera Universita di Bolzano, Italy \\ marco.bietresato@unibz.it
}

\begin{abstract}
In the development of a transportable test-system for the on-site detection of many technical parameters concerning agricultural engines, two concurrent but conflicting needs have to be managed: (1) having a high degree of completeness (and compactness) of the equipment, (2) coordinating the acquisitions from several instruments by using a possibly unique acquisition clock (i.e., with the same time interval and acquisition instant). For the first point, the ideal solution is to have as many test-instruments as possible, however, all transportable with a single vehicle and, possibly, requiring a monophasic 230-VAC power supply (i.e., available in any civil building, including farms); instead, the second point may imply a much higher complexity to be addressed. Despite it, it is possible to select and purchase only instruments with the same type of data-output (e.g., serial), the acquisition rates can be very different, due to the different types of instruments and operating principles. Also, sometimes the data interfaces cannot even be available (e.g., for dynos) and it must be created ad hoc by arranging external integrated circuits to be connected to the test devices. In the present work we illustrate the solution that has been reached in the creation of an integrated mobile test-system for agricultural machines, part of the equipment of the "Agroforestry Innovation Laboratory" of the Free University of BozenBolzano. It is based on a LabVIEW system with a graphical user-interface able to: (1) simultaneously acquire data from a trailed PTO-dyno, a chrono-gravimetric fuel-consumption meter, an exhaust-gas chemical analyser and a datalogger with different thermocouples connected to it, (2) display in real time the value of any acquired parameter, (3) plot in real time the usual motor-performance graphs (torque and power as a function of the engine speed) and other time-dependant graphs, (4) save the acquired data in a format compatible with the most common spreadsheets (in particular, MS Excel). The torque and power data have been validated in a comparative test of the integrated system with the original software of the dyno, obtaining very small differences (lower than $3.1 \%$ ). The user interface has been developed in accordance with the good-design guidelines for software, thus resulting to be highly usable in carrying out its functions, i.e. having a high level of efficiency and effectiveness.
\end{abstract}

Keywords: agricultural machines, engine performance, test-equipment, PTO-dynamometer, dyno-test, LabVIEW interface, real-time detection.

\section{Introduction}

The need for measuring physical quantities is connatural to the scientific research since its dawn, considering also that all non-abstract subjects are based on a quantitative approach to reality, deriving from the mathematical-physical component at their basis. For this reason, the development of measurement systems has always accompanied the development of basic and applicative scientific disciplines, as well as new measurement needs have, in some way, pushed the technique to develop ever-new acquisition systems. Over the years, the measuring instruments have undergone an almostconstant evolution that has also included the transition from an analogue to a digital architecture, thanks to the introduction of the concepts of: (1) transduction of a signal and (2) sampling of an analogical electric signal. However, evolution has not always been coherent in all areas and the overlapping of the various standards over the years, the constant expansion of the scientific domain of investigation and the use of different measurement principles have led to an extremely-inhomogeneous situation, despite the coding of a series of standardized electronic and computerized interfaces. The outlined situation is sometimes difficult to master by an experimenter who wants to channel the signals in the same repository, and it can become even more critical, when there is also the technical need of portability for each instrument. Indeed, this further requirement can limit the choice to only those models that can be more practical (i.e. compact and light-weighting) to be transported and placed near the system to be monitored, moving the communication and interfacing needs to the background.

This situation is exactly the same afforded by us, when we set the goal of developing a transportable test-system for the on-site detection of many technical parameters concerning agricultural engines. A system of this type can be extremely interesting to widen the possibility of 
testing agricultural machinery by a research board: such a relocatable system has the characteristics of a scientific measurement system (i.e., a high precision) and would allow providing a highly-qualified service to the territory. It is necessary that such a test system is composed of many different scientific instruments [1], which possibly detect simultaneously different physical quantities, thus allowing the investigation of the energetic and environmental performances of an engine at different rotational speeds [2;3], maybe with different fuels [4-6] or at different positions of the accelerator pedal, i.e. with different fuel-admission conditions.

The synchronization of the readings from various instruments could surely be performed ex post by using a calculation program, if each of these instruments recorded even the acquisition time and their internal clocks had all been previously synchronized [7-10]. However, this post-processing operation is never simple: even if it is possible to select and purchase only instruments with the same type of data-output (e.g., serial), the acquisition rates can be very different, due to the different types of instruments and operating principles. Rather, in this case, the best solution is the development of a control system that puts at the experimenters' disposal a unique automation interface to control specific functions of the connected instruments during the trials $[11 ; 12]$ (thus implementing the socalled "Computer-Aided Testing"). Therefore, such a system should be developed before the experimental sessions (ex ante) and, therefore, should be already active at the time of experimentation, thus allowing the experimenters to be relieved of the burden of synchronizing the clocks and, then, of coordinating the readings. The best solution would be the use of coordination software/hardware, which manages to: (1) start all the individual instruments connected to it, (2) gather the data collected by them and (3) save them, synchronized, in a single file containing all the acquired data, typically a text file. This file can be subsequently imported in a spreadsheet (e.g., MS Excel or LibreOffice Calc), in some cases after a proper processing, as in [13]. Therefore, the flow of signals should be fully bidirectional (control signals, acquisition data). However, there is also another simpler solution for the connections, i.e. unidirectional: all the readings are made available from each instrument since its start and conveyed into a single storage subsystem without any control signal from a central unit. In this case, the problem of communication between each single measuring instrument and the central unit, even if reduced in its complexity because unidirectional, still exists. Focussing the attention on the hardware of such acquisition systems for engine tests, in [14] an Arduino microcontroller is used as a data logger connected to a PC via a USB port. Up to seven sensors were connected to this open-source and cheap board. In [15], a cRIO module and a digital-input 9401 board both by National Instruments are used; this is a surely-interesting solution, however, in the proposed configuration, interfaced only with two sensors of the same type, so used in a relatively-simple instrumental layout. In [5], the highfrequency acquisitions concerning the amount of injected bioethanol per cycle and the in-cylinder pressure in a compression-ignition engine are managed by dedicated subsystems (respectively: cRIO 9022 by National Instruments and MicroIFEM by AVL). In the engine test bench described in [16;17] a Keithley KPCI-3110 data acquisition board is used. In this case, the acquisitions must be addressed by a dedicated board due to the high performances (i.e., a 12-bit resolution at an acquisition speed of 1.25 MS $\cdot \mathrm{s}^{-1}$ ) needed by a system capable of measuring the pressure in the diesel fuel injection and in the combustion chamber. The same need is present in [18;19], where an IndiModul 622 by AVL is used. AVL offers also an interesting software solution, i.e. the PUMA Open System, to manage many instruments and create a so-called "configurable device handler" that has a unique software interface to coordinate all the connected devices [12]. LabVIEW by National Instruments is another software environment that is used for this purpose [20]. Both PUMA and LabVIEW abstract the complexity of the equivalent lower ISO/OSI layers [21], providing the client with a generic interface.

Finally, even when it is possible to develop an adequate software system (therefore, effective in relation to the purpose for which it is developed, i.e. collecting data from many sources), little importance is given to the interfaces, with the result of having systems that are objectively difficult to be used (therefore, not very efficient). In fact, the persons who develop these interfaces are usually experts in the systems under monitoring, but not in monitoring systems (i.e., they are not software developers). Actually, the principles to be applied to make a user interface better are all simple and well codified, even by international standards [22-24].

Therefore, the aim of this work was the development of an integrated system for the real-time detection and recording of many engine parameters of agricultural machines during dyno tests, 
through a series of connected portable instruments, presenting also a very simple and effective user interface.

\section{Materials and methods}

The integrated system has been developed by following the phases listed hereinafter:

1. Concept of the system; enumeration of the technical requirements that such a system should be able to satisfy; drafting of a basic layout for the system (classification and choice of instruments; map of connections, identification of the general control unit and of the unit to be used for data saving, if different from the control unit);

2. Preliminary checks; verification of the technical characteristics of the control unit and of the instruments to be connected (physical interfaces and communication protocols); software setup of the instruments and possible hardware modification to prepare all the units to communicate with the control unit;

3. Building of the system; creation of a proper software program for managing the instruments, in particular: (i) setting up of a "push" or "pull" data-acquisition strategy (i.e., interrogation of the instrument or reading/interception of data already made available by the instrument) for each element to be connected according to the level of access to the instrument language, (ii) search for software libraries or ready-made parts of code, (iii) program writing and verification of the correct operation of each part of code (the system becomes incrementally more and more complex), (iv) creation of a user interface based on the principles of human-centred design and software usability, (v) creation of a data saving/export subroutine and setting of an output file structure (format, column arrangement);

4. Verification of the system; verification of the correct operation of the management software by connecting one instrument at a time (verification of the system by parts, even with simulated input signals); verification of the correct interpretation of the signals converging in the control unit by comparing the readings of the same systems when stand alone; verification of the correct operation of the whole system in a general test with all the instruments connected to the control unit; setting of the optimal working parameters for all the units, in particular selection of the correct general acquisition frequency, taking into account: the different acquisition logics (point 3.i of this list), the response speed of each instrument, the rate of change of the parameter to be detected and, eventually, the experimenters' needs in terms of number of points to be recorded during a single trial.

Even if considering that all measurements are more or less directly related to the engine of the agricultural machine under test, the technical requirements of the system can be classified by domain of relevance (i.e. by the direct object of measurement):

- motor: detection of instant torque, instant power, instant brake specific fuel-consumption (BSFC), temperature in several points of the motor and of the exhaust line (e.g., downstream and upstream the turbine, at the exhaust manifold, at the exhaust pipe);

- exhaust gas: chemical composition of the main polluting species, temperature of the gas;

- fuel: instant quantity in an external tank (part of a fuel-consumption meter), temperature (at the external fuel-supply tank).

At the same time, a further classification, based on the instruments able to perform each of the above-listed measurements [25], has been performed (see Table 1):

- PTO-dynamometer: detection of instant torque, instant power, instant PTO rotational speed;

- chrono-gravimetric fuel-consumption meter system (i.e. the plate scale): instant quantity of fuel in an external tank, useful to calculate the instant BSFC of the tested tractor [26];

- gas analyser: chemical composition of the main polluting species, temperature of the gas;

- universal datalogger (cool-junction-compensated inlet ports for thermocouples): temperature in several points of the motor and of the exhaust line (e.g., downstream and upstream the turbine, at the exhaust manifold, at the exhaust pipe), temperature (at the external fuel-supply tank). 
Thanks to the proposed classifications of the technical requirements, it has been possible to understand which instruments should have been used and, therefore, would have been part of the acquisition system (Table 1).

Table 1

Components composing the integrated system for the real-time detection and recording of many engine parameters, together with their main technical specifications

\begin{tabular}{|c|c|}
\hline $\begin{array}{c}\text { Test equipment, } \\
\text { manufacturer, model }\end{array}$ & Technical specifications \\
\hline $\begin{array}{l}\text { Electric mobile test } \\
\text { stand (PTO- } \\
\text { dynamometer), } \\
\text { J. Froment \& Co Ltd. } \\
\text { (Easton-on-the-Hill, } \\
\text { East Northamptonshire, } \\
\text { England, UK), Sigma } \\
50 \text { Mobile [27] }\end{array}$ & $\begin{array}{l}\text { - It has a maximum power of } 380 \mathrm{~kW} \text {, a maximum torque of } \\
3170 \mathrm{Nm} \\
\text { - It is manually-operated through a hand-held terminal } \\
\text { - It can operate according to two main test programs: speed-controlled } \\
\text { mode (i.e. the operator sets a PTO-speed and the dyno keeps that } \\
\text { speed constant), full-automatic mode (the dyno applies an increasing } \\
\text { breaking torque at the PTO pinion, thus detecting the torque and the } \\
\text { power in the complete speed-range of the motor) } \\
\text { - It is equipped with an internal electric generator and a series of } \\
\text { resistances for dissipating the kinetic energy transmitted from the } \\
\text { tractor in test to the dyno, converted in electric energy by the } \\
\text { generator } \\
\text { - It requires a temporary connection with the electric grid (single- } \\
\text { phase } 230-\mathrm{V} \text { alternated current, } 50 \mathrm{~Hz} \text { ) to supply the electronic } \\
\text { control unit during the execution of a test } \\
\text { - It is not equipped with a data interface, so a proper modification was } \\
\text { required }\end{array}$ \\
\hline $\begin{array}{l}\text { BSFC } n \\
\text { equipme } \\
\text { consum } \\
\text { system) }\end{array}$ & $\begin{array}{l}\text { - Functioning principle: chrono-gravimetric (a Diesel oil tank is } \\
\text { placed on a precision scale, the mass decrement is measured over } \\
\text { the time) } \\
\text { - The plate scale is "DS } 30 \mathrm{~K} 0.1 \mathrm{~L} \text { " by Kern \& Sohn } \mathrm{GmbH} \text { (Balingen, } \\
\text { Germany); maximum load } 30.1 \mathrm{~kg} \text {; readability } 0.1 \mathrm{~g} \text {; repeatability } \\
0.2 \mathrm{~g} \text {; linearity } 0.5 \mathrm{~g} \text {; plate dimensions } 450 \times 350 \times 115(\mathrm{height}) \mathrm{mm} \text {; } \\
\text { power supply: single-phase } 230-\mathrm{V} \text { alternated current, } 50 \mathrm{~Hz} \text { [28] } \\
\text { - RS-232 data interface; sampling frequency } 1 \mathrm{~Hz}\end{array}$ \\
\hline $\begin{array}{l}\text { Portable gas a } \\
\text { MRU Instrum } \\
\text { (Houston, TX, } \\
\text { Vario plus Ind }\end{array}$ & $\begin{array}{l}\text { - This instrument is able to measure up to nine different gas species } \\
\left(\mathrm{O}_{2}, \mathrm{CO}, \mathrm{NO}, \mathrm{NO}_{\mathrm{x}}, \mathrm{CO}_{2}, \mathrm{NO}_{2}, \mathrm{SO}_{2}, \mathrm{H} / \mathrm{S}, \mathrm{HC}\right) \text {, thanks to two } \\
\text { different measurement principles (electrochemical, infrared) } \\
\text { - Gas temperature measurements: up to } 1100^{\circ} \mathrm{C} \\
\text { - Integrated gas-cooler and automatic condensate-draining pump } \\
\text { - RS-232 data interface; sampling frequency: } 1 \mathrm{~Hz}\end{array}$ \\
\hline $\begin{array}{l}\text { Universal datalogger, } \\
\text { Thermo Fisher } \\
\text { Scientific Australia Pty } \\
\text { Ltd. (Scoresby, VIC, } \\
\text { Australia), Datataker } \\
\text { DT85M }\end{array}$ & $\begin{array}{l}\text { - Analog inputs: } 48 \text { (2-wire common reference), } 32 \text { (2-wire isolated), } \\
16 \text { (3 and 4-wire isolated) } \\
\text { - Analog input range: voltage } \pm 30 \mathrm{mV}, 300 \mathrm{mV}, 3000 \mathrm{mV} \text {, } \\
50000 \mathrm{mV} \mathrm{DC;} \mathrm{current} \pm 30 \mathrm{~mA} \text {; resistance } 1 \mathrm{M} \Omega \text {; frequency: } \\
450 \mathrm{kHz} \\
\text { - Digital I/O: } 8 \text { bi-directional channels } \\
\text { - Counters: } 8 \text { low-speed counters, shared with digital inputs, } 7 \\
\text { dedicated counters, with a high speed or } 3 \text { for a phase encoder } \\
\text { - Power requirements: } 10-30 \mathrm{VDC} \\
\text { - USB data interface; maximum sampling rate: } 40 \mathrm{~Hz} \\
\text { - Five thermocouples (type: } \mathrm{K}, \mathrm{J}) \text { are actually connected to it to } \\
\text { monitor the temperature of several points in the motor/exhaust line }\end{array}$ \\
\hline
\end{tabular}


All these instruments had to be coordinated by a super-subsystem (i.e., a control unit), which, in this case, has been delineated to be a PC equipped with a proper software and an adequate number of serial interfaces. It is worthy to notice that this solution is more flexible and easier implementable than a configuration using a data logger to coordinate all the instruments, especially considering the PTOdyno interfacing. In the proposed general system architecture, the data logger is exploited firstly as a port multiplier, and secondary for its easiness of managing thermocouples (thanks to several cooljunction-compensated inlet ports). A possible use of it to coordinate all the instruments (i.e. as control unit) is, in this case, difficultly implementable. The resulting architecture is therefore a hierarchical tree (Fig. 1).

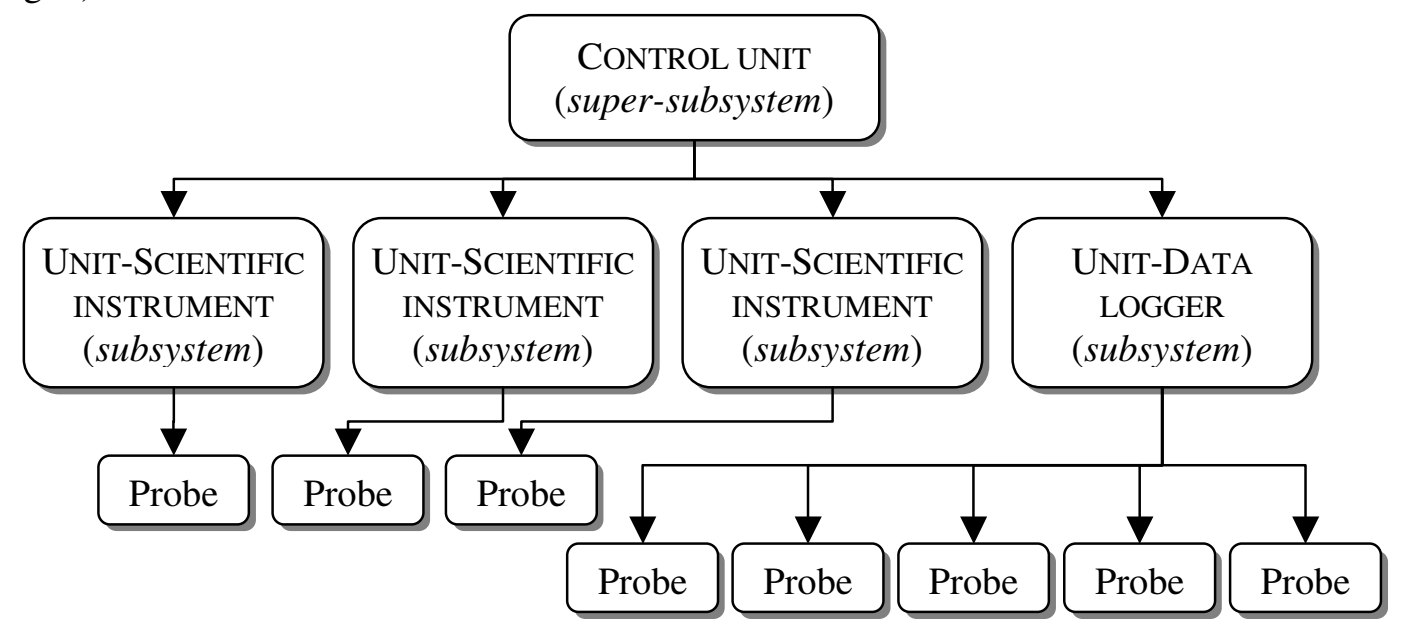

Fig. 1. General architecture of proposed integrated system

The development of the user-interface was inspired by software ergonomic principles, which basically forecast a user-centred design and introduce the concept of software usability (ISO 9241-10, ISO 9241-11, ISO 9126) [22-24]. According to D. Norman [29] the usability of a software product measures the cognitive distance between: (1) the model of the designer, i.e. the model of the product and of its mode of use that the designer has (based on his knowledge) and that has been incorporated into the product, and (2) the model of the user, i.e. the model of operation for that product that the user builds in his mind (always based on his knowledge and skills) and which regulates the interaction with the product itself. The ultimate goal of usability is "making invisible, transparent the underlying technology to the user", to let the user focus attention only on the tasks, using easily the software.

The ISO 9241-10 standard [22] defines the principles that characterize the so-called "humancomputer dialogue", and, in particular, this dialogue must be designed in such a way that it results:

- suitable for the task and self-descriptive, then it must clearly make understand the operation that the user had to perform at that precise moment;

- user-controllable, i.e. it must allow some interactivity with the user (e.g. request of confirmation, sending of an informative message);

- corresponding to the user's expectations, so the information should be presented in a way that is easily comprehensible by the user;

- error-tolerant, in particular it must avoid errors by users, asking for confirmation of important operations, allowing a step back in case of error (recovery action);

- $\quad$ suitable for personalization and learning, i.e. it must be quickly learned in all its functions.

\section{Results and discussion}

The integrated system is visible in Fig. 2. It is composed by four measurement units physically connected to a personal computer on which has been installed an ad-hoc-developed software program; counter clockwise in Fig. 2 there is: the plate scale (component of the fuel-consumption measurement system), the data logger with several thermocouples connected to it, the gas analyser, the PTO-dyno (through its hand-held terminal).

Except for the dyno, all these units were already equipped with a serial interface for data, so their physical connection to the computer (i.e. the wiring) was very easy. Instead, the PTO-dyno had no 
interface to be used (1) for the collection of the data or (2) for its control, by giving a start/stop signal. For this reason, the connection of the dyno to the acquisition system had deserved deep thinking, involving the architecture of the system on more than a level (physical connection, software management) and started from the controlling modes for the dyno.

Indeed, the dyno can be usually controlled in two ways:

- through a personal computer, on which the user has to install a proprietary software (Sigma DynaTest by J. Froment \& Co Ltd.); the personal computer is then connected to the PTO-dyno through a USB cable and a proper signal-converting unit, needed to interface the USB protocol to the serial protocol of the dynamometer (requiring a 10-pin round connector); the communication between the computer and the dyno is therefore bidirectional (from PC to the dyno: operation-mode set-up, test-start signal; from the dyno to the PC: measured power and torque data, PTO-speed, test-stop signal);

- through an additional control unit, i.e. the hand-held terminal, to be connected via a 10-metre cable to the dynamometer control panel located in the front cabinet, having a simple user interface that allows configuring the dyno for the test and selecting the control mode (e.g. speed-controlled); the functionalities of this terminal are the same of Sigma DynaTest, except it does not allow a graphical representation of performances curves (only maximum/minimum values are displayed) and a permanent data-storage (its memory is overwritten at the beginning of a new test); also in this case, the communication between the computer and the terminal is bidirectional (from the hand-held terminal to the dyno: operation-mode set-up, test-start signal; from the dyno to the hand-held terminal: measured power and torque data, PTO-speed, test-stop signal).

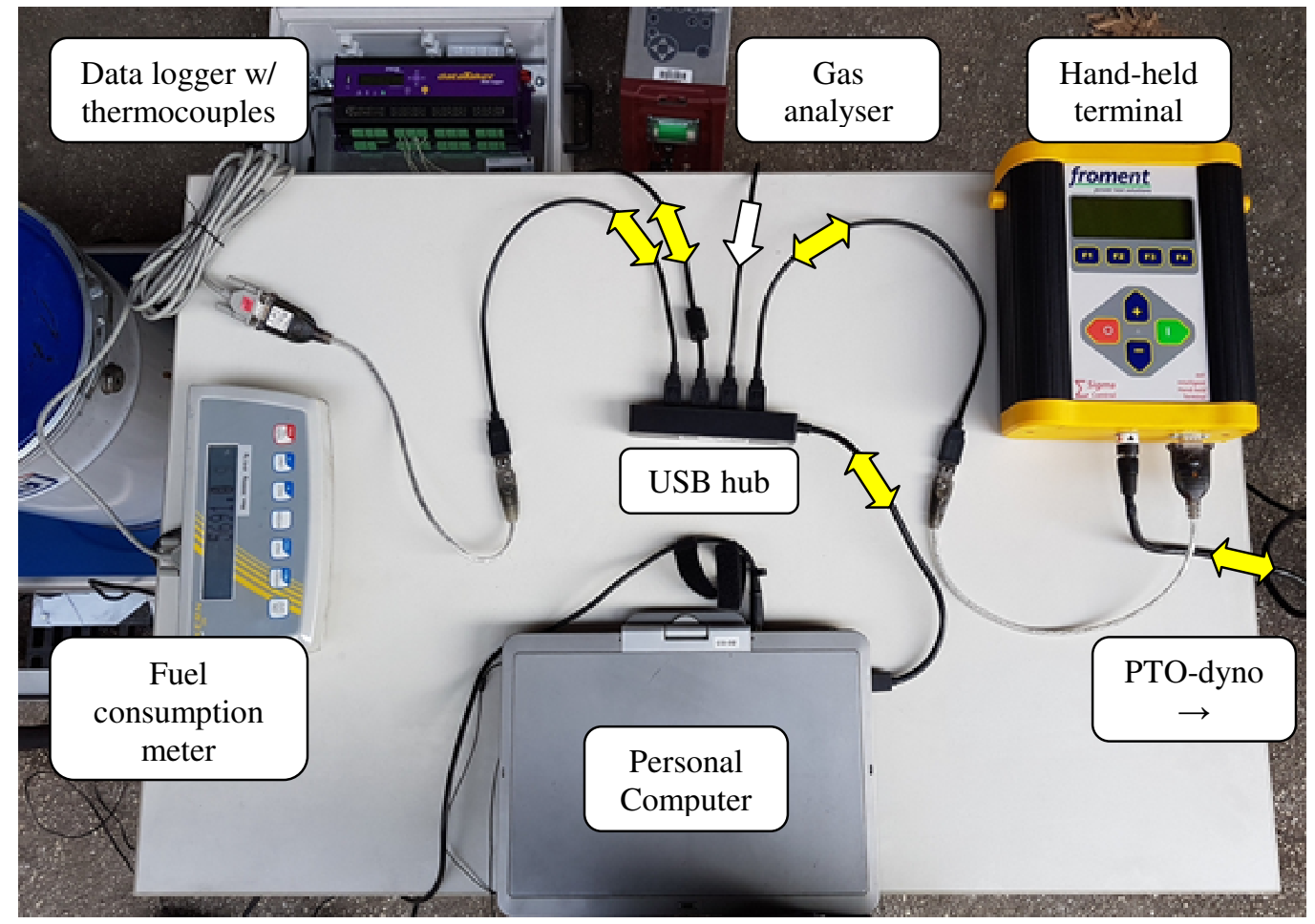

Fig. 2. Wiring layout of different instruments connected together to compose integrated acquisition system (NB: PTO-dyno is outside the photograph); the white/yellow arrow indicates a unidirectional/bidirectional flow of signals in that wire

The need for a software-system substituting the proprietary software program in the full control of the dyno comes from the impossibility to modify the proprietary software to (1) implement new functionalities and (2) let it save data from other instruments than the dyno itself. Indeed, as the J. Froment \& Co Ltd., manufacturer of the dynamometer, gave us access neither to the high-level communication protocol used by the Sigma DynaTest software to communicate with the dyno through the USB port, nor to the source-code of the Sigma DynaTest software, it was impossible for us to 
exploit this system to build a new, more integrated software program (by extending the functionalities of Sigma DynaTest). So, under the suggestion of our reference in Froment, we individuated as the only viable solution to query periodically the hand-held terminal to return the instant value measured by the dyno. To do so, a new RS-232 serial interface had to be added in the hand-held terminal, by manually soldering three terminals to the PCB of the terminal and milling an opening in the external case to accommodate the RS-232 socket (Fig. 3). This interface was useful to connect the hand-held terminal to a computer via a USB port, by using a RS232-to-USB converter (usually called FTDI cable) and a proper computer-driver.
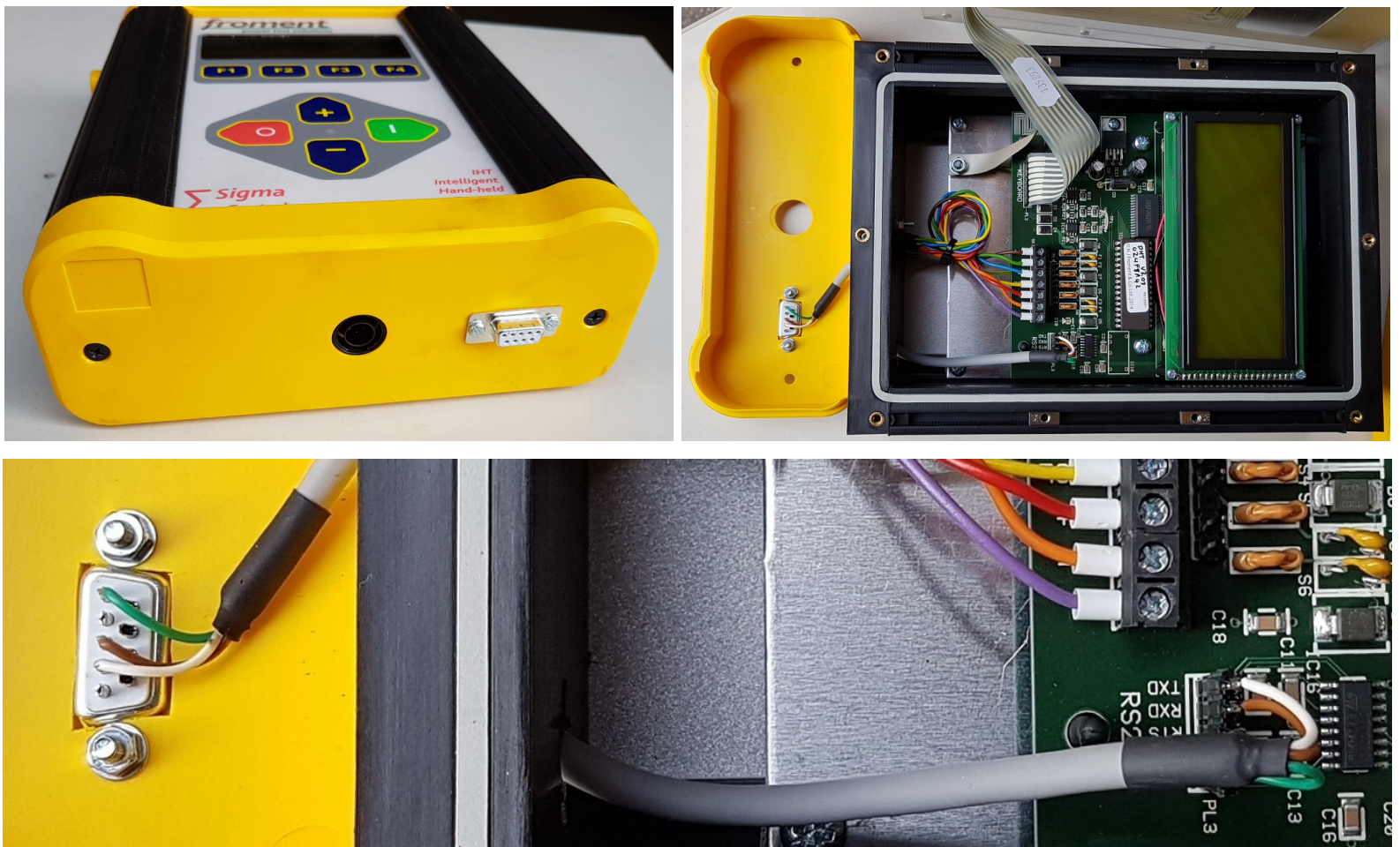

Fig. 3. Hand-held terminal of Froment dyno with added serial-interface in evidence on its bottom side (top left); (top right) interior of hand-held terminal; (bottom) close-up view of connection between PCB and RS-232 serial interface; notice that only three pins of socket have been used

It is worthy to notice that the connection of the computer to the hand-held terminal is bidirectional, but has some limitations: the terminal sends a datum to the computer only when the computer asks for a reading to the dyno, but the computer cannot control the start of the braking action of the dyno on the tractor PTO-shaft. The consequence is that the acquisition of the data from the various instruments and the control of the dyno are performed by two different entities, respectively: the software program installed on the computer and the hand-held terminal of the PTO-dyno. The operator has therefore the need to start both systems, as evident also in the codified general four-step operating procedure, here reported:

1. Physical installation of instruments and probes on the agricultural machine to be tested

- connection of the tractor PTO to the dynamometer when the engine is off;

- installation of the fuel-consumption meter;

- positioning of all the thermocouples and of the sampling probe for the exhaust gases;

- ignition of all instruments, of the computer and of the dynamometer;

2. Start of the acquisition system

- connection of one instrument at a time to the USB-hub (hence to the computer), in order to set for each instrument the correct COM-port on the software interface;

- naming of the file that will collect all the data of the test and setting of the mass-memory location that will store the file; 
3. Start of a test on an agricultural machine with the simultaneous acquisition and recording of engine parameters

- ignition of the tractor, set of the accelerator pedal at its maximum;

- start of data acquisition on the computer (by clicking on the start button in the user interface);

- start of the control of the PTO/engine speed (manual speed-controlled test) or start of an automatic test cycle via the hand-held terminal (by pushing the start button);

- end of data acquisition in the computer and automatic saving of acquired data in the hard-disk of the computer (by clicking on the stop button in the user interface, only after the test has ended, i.e. the breaking torque has been released);

\section{End of a test session}

- switching off the motor of the tractor and of all other measurement instruments.

The management of all hardware interfaces and signals, conveyed through these serial interfaces, was carried out through a program (namely "TRA-LOG", contraction of "farm tractor logging software") written in the visual-programming language " $G$ " within "LabVIEW 2017" version 17.0f32, the integrated development environment by National Instruments Corporation (Austin, Texas, USA). Within LabVIEW, the programmer connects different function-nodes by drawing wires. These wires propagate variables and any node can execute its task as soon as all its input data become available. The LabVIEW-source code has therefore the form of a graphical block diagram, guiding the execution flow left to right like a liquid flowing in a pipe network. LabVIEW was chosen among all possible programming languages, because it allows easy creation of user interfaces ("front panels"), perfectly integrated with the graphical code below ("block diagram") to be executed, thus forming a so-called "virtual instrument" (VI). A front panel is built using "controls" and "indicators". Controls are input objects: they allow a user to supply information to the VI. Indicators are output objects: they indicate, or display, the results based on the inputs given to the VI. The back panel contains the graphical source-code (Fig. 4, Fig. 5). All the objects placed on the front panel will appear also on the back panel. The back panel also contains structures and functions which perform operations on controls and supply data to indicators. The interfacing of this system with the Datataker unit has been possible thanks to a proper library.

The user interface has been designed according to the principles of user-friendliness and easy usability, by organizing hierarchically the information through the use of colours and layers (panels). In particular, the user interface is made up of three superimposed tabs (i.e. "front panels" in LabVIEW), sorted according to a level of decreasing importance for the end-user.

The first tab is the main tab (Fig. 6); it is always visible at the system start and has two parts:

- a very simple light-blue control panel with three drop-down menus ("controls" in the LabVIEW manuals) to setup the COM ports (respectively for: the dyno, the scale, the gas analyser), a "clear all graphs" button, a "start" button and a "stop" button, identified by the usual traffic-light colours (respectively: yellow, green, red); the user can interact with the system only through the objects with a white background, e.g. some textboxes, in which writing the location where the thermocouples have been placed;

- the rest of the interface, having a light-grey colour, containing some elements ("indicators" in the LabVIEW manuals) to display a series of parameters graphically (on the top left: area for the tracing of the classic performance and torque curves, on the top right: areas for plotting the graphs showing the temporal trend of the parameters of the engine, torque, power, rotational speed, or, in the bottom right, the mass of fuel in the external tank of the consumption meter) or numerically (in the bottom centre: boxes showing the instantaneous concentration of some chemical species in the exhaust gases, in correspondence to each clock stroke of the system).

In the second tab, i.e. the parameters tab (namely "Parametri"; Fig. 7), the user has the possibility to modify some very specific control parameters (to be changed only if the system does not work properly in a test session), and to check the correct operation of the system by accessing the data strings sent by the gas analyser (one of the most critical instruments to have been connected to the system).

The third tab, i.e. the help tab (indicated to as “?”; Fig. 7), gives the user: 
- a short description of the system functionalities (first paragraph);

- the list of the preliminary operations to start the system (second paragraph);

- the procedure to start/stop the acquisition and save the data (third paragraph).

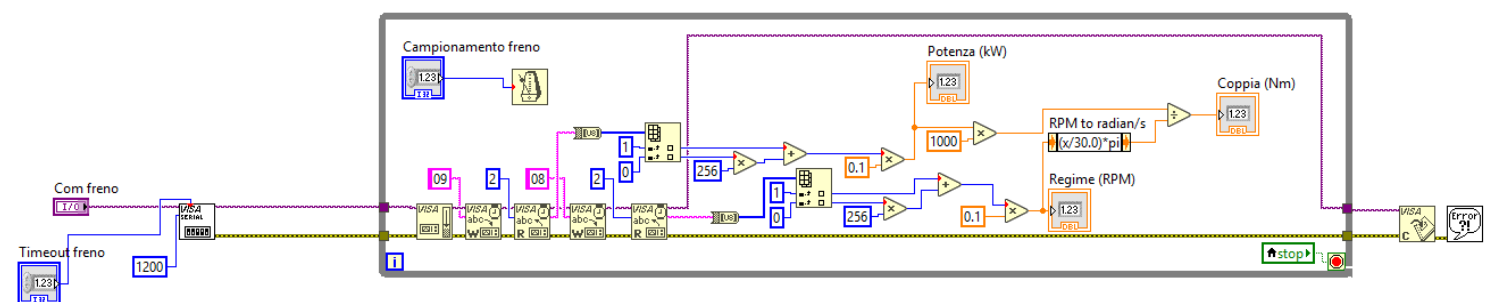

Fig. 4. Block diagram of integrated system, part of it in charge of processing data flow from PTO-dyno and sending them, processed, to front panel; grey frame is do-while loop

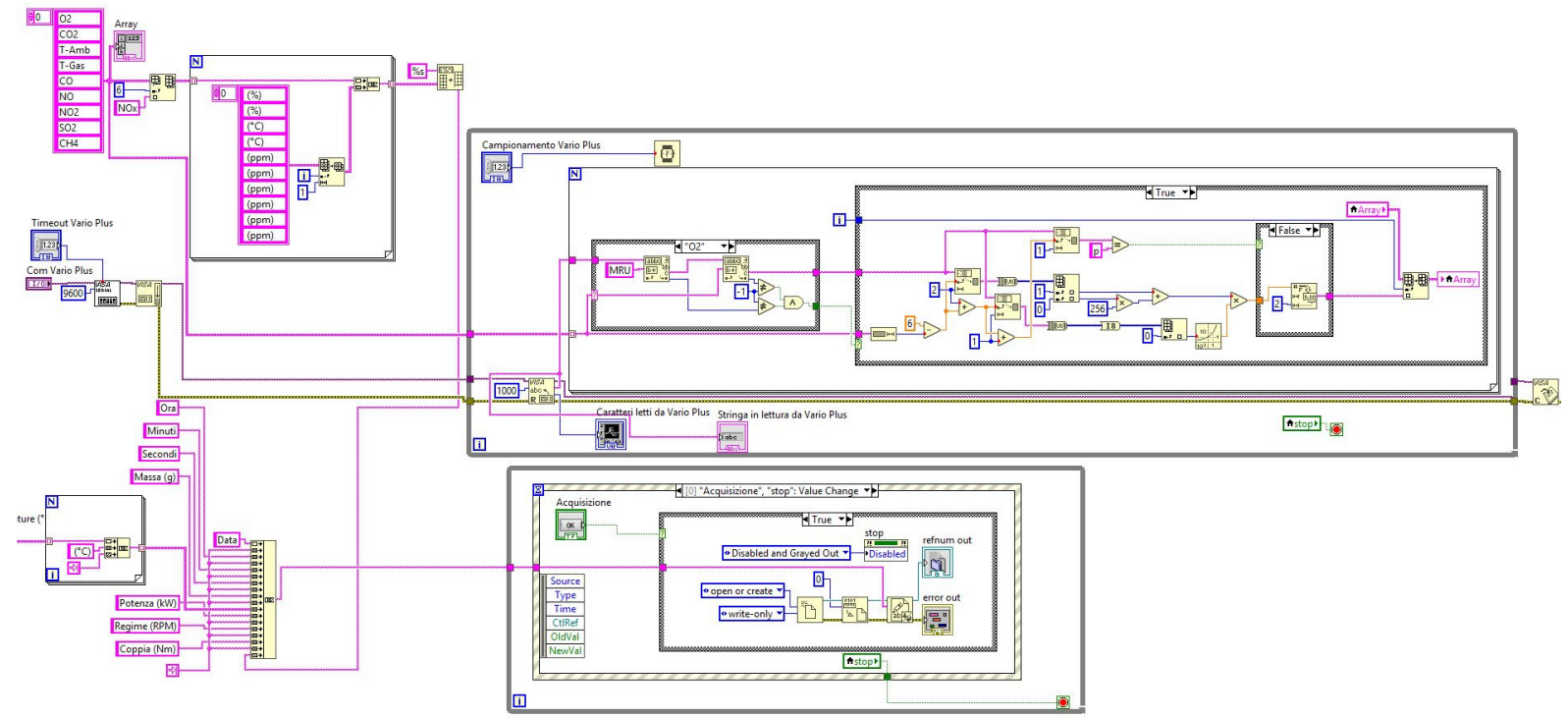

Fig. 5. Block diagram of integrated system, parts of it in charge of processing data-flow from gas analyser (top grey frame) and creating file in which saving all data with proper headings (bottom grey frame)

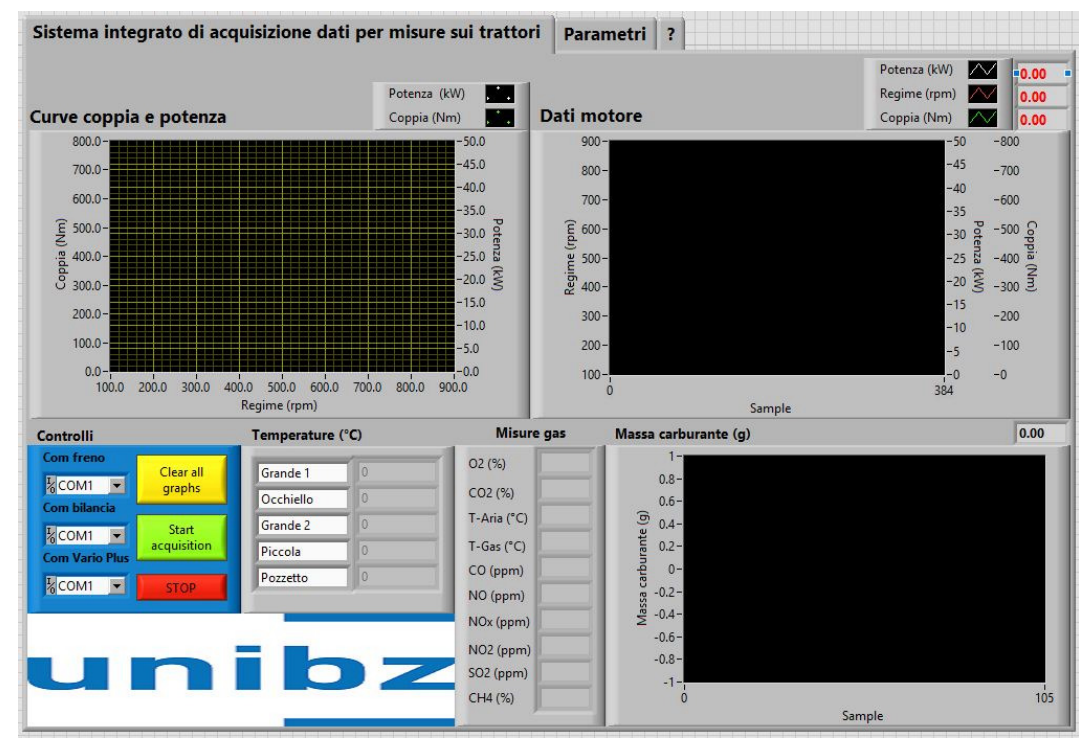

Fig. 6. Main tab of visual interface of "TRA-LOG" system; in the bottom-left angle there is the control panel (namely "Controlli") with the necessary items (drop-down menus, buttons) usable by the operator, while the remaining part of the screen is used to visualized the acquired signals 


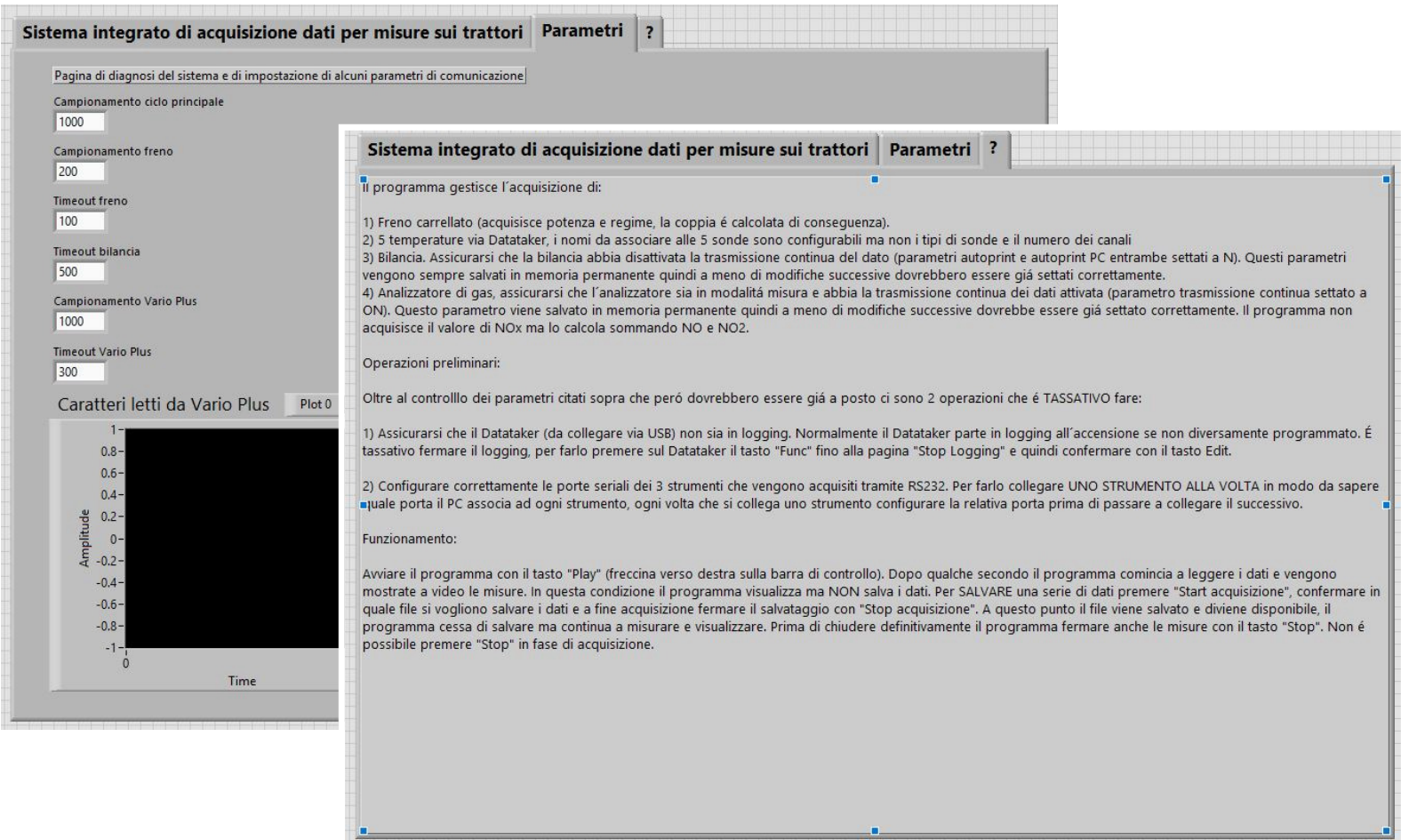

Fig. 7. Secondary tabs of visual interface of integrated system (parameters tab or "Parametri"; help tab indicated to as "?")

Speaking from the point of view of the software usability, i.e. by the number of possible errors made by the user in completing a task (here: the acquisition of many engine parameters), the proposed interface resulted to be very efficient. Indeed, in this case:

- the start and stop procedure is immediate and there is an immediate feedback for these actions: thanks to LabVIEW pre-set functionalities, a click on a button changes its appearance (so as the button seems really pressed) and the data recording starts (graphs begin to be plotted);

- no unwanted action can be performed by the user (the interaction with the system is limited to three intuitive buttons and some textboxes);

- there is a coherent flow for settings (left to right in the first tab) and there are no submenus;

- the layout is simple and schematic, with all important information and controls in the foreground.

The acquisition system was then tested in all its functions (i.e., data acquisition and file saving) in the first test on a New Holland T4020V farm tractor fuelled with conventional diesel oil, stabilized at a constant engine speed. The sampling rate of the acquisition software "TRA-LOG" was set at $1 \mathrm{~Hz}$, i.e. at the lower value of all the acquisition rates of the connected instruments, and no problem of data reception by the control unit arose. Instead, the validation of the system concerned specifically the torque and power data from the dyno, as this was the most critical device that has been connected to the system. The validation experiment was made up of two trials (Fig. 8):

- the first trial made use of the acquisition software presented here (TRA-LOG); for this trial, the automatic-test mode was chosen on the hand-held controller of the PTO-dyno; in this operating mode, the dyno applies through the PTO an increasing braking torque to the tractorsystem at full throttle (i.e. at the maximum fuel-admission to the injection pump); all data were then saved in a text file with tab-separated values and subsequently imported into MS Excel for further processing (e.g., [30]);

- in the second trial, the motor torque and power of the same tractor were also detected using the Sigma DynaTest system (operating mode: automatic test), in order to have data, warranted by the manufacturer of the dyno, to be used to compare the acquisition system output for what concerns the torque and power data from the dyno. Notice that also the data coming from the 
other devises were recorded in this trial, even if they are really interesting only when the engine is manually operated, i.e. stabilized at set PTO-speeds.

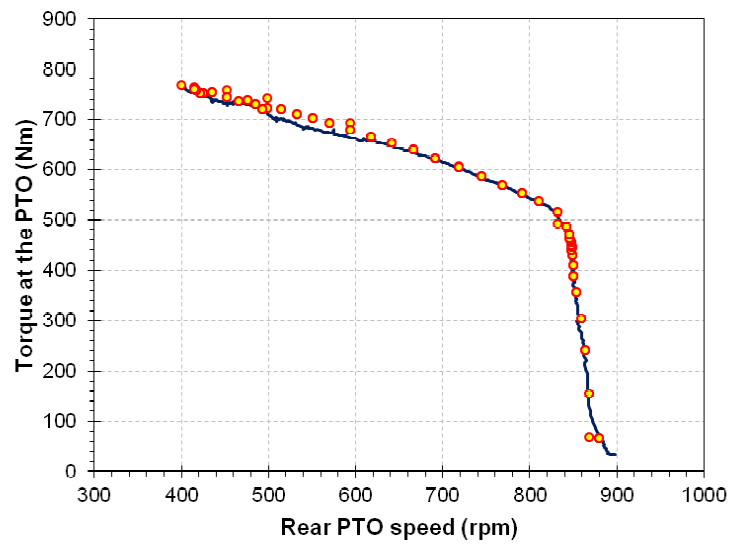

- Sigma DynaTest $\quad \circ$ Acquisition system

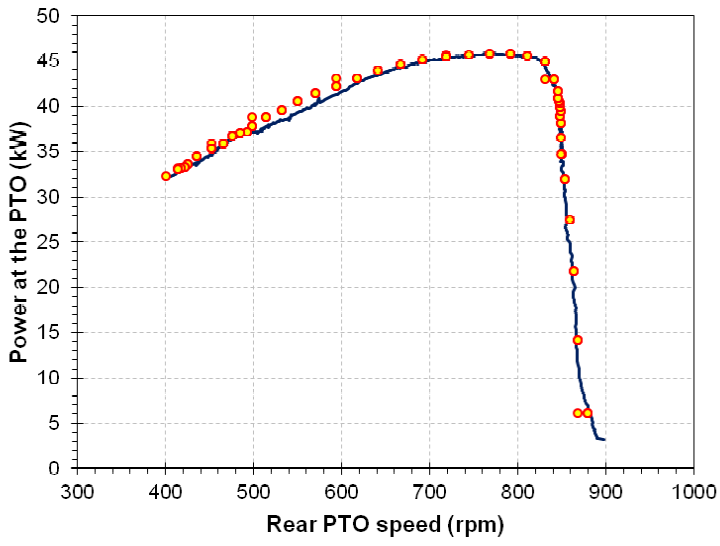

- Sigma DynaTest $\quad$ Acquisition system

Fig. 8. Torque (left) and power (right) at PTO of New Holland T4020V tractor, detected by using two systems (Sigma DynaTest by Froment and Acquisition System developed by Unibz)

The first observation can be done after observing the graphs of Fig. 8: the reduced number of experimental points, characteristic of the TRA-LOG acquisition system (it has a constant sampling rate of $1 \mathrm{~Hz}$ and a complete trial has a duration shorter than 3 minutes, in this case $145 \mathrm{~s}$ ), is however sufficient to have a good delineation of the engine characteristic curves. In the analogous automatic test, the Sigma DynaTest system has stored up to 1834 points, unfortunately not with a constant sampling rate (the sampling rate ranges from 8.0 to $16.1 \mathrm{~Hz}$, with an average of $13.0 \mathrm{~Hz}$ ).

Comparisons were made on the basis of the absolute percentage error on the torque and power at the PTO in the 400-800 rpm PTO-speed interval (i.e. corresponding to the engine operative range), taking as a reference the acquisitions of Sigma DynaTest. The formula used for the power is the following, where the average values have been introduced to manage the multiple values of power referred to the same PTO speed $n^{*}$ taken without decimals (for the torque the formula is analogous):

$$
\varepsilon_{P\left(n^{*}\right)}=\left|\frac{\frac{\sum_{i=1}^{s} P_{j, \text { Acq. System }}\left(n^{*}\right) \sum_{j=1}^{t} P_{i, \text { Sigma DynaTest }}\left(n^{*}\right)}{t}}{\frac{s}{\sum_{j=1}^{t} P_{i, \text { Sigma DynaTest }}\left(n^{*}\right)}}\right|=\left|\frac{\bar{P}_{\text {Acq.System }}\left(n^{*}\right)-\bar{P}_{\text {Sigma DynaTest }}\left(n^{*}\right)}{\bar{P}_{\text {Sigma DynaTest }}\left(n^{*}\right)}\right|
$$

where $\varepsilon_{P\left(n^{*}\right)}$ - percentage error on power recorded at the PTO at a set PTO-speed $n^{*}, \%$;

$P_{j, \text { Acq.System }}\left(n^{*}\right)-\mathrm{j}$-th value of power at the PTO at the PTO-speed of $n^{*}$, recorded through the TRA-LOG acquisition system, $\mathrm{kW}$;

$P_{i, \text { Sigma DynaTest }}\left(n^{*}\right)$ - i-th value of power at the PTO at the PTO-speed of $n^{*}$, recorded through the Sigma DynaTest system, kW.

As visible in Fig. 9, all percentage errors are fairly below $4 \%$ (precisely, the maximum error is $3.1 \%$ on the torque and $3.0 \%$ on the power, and the average errors are $1.1 \%$ and $1.2 \%$ respectively), thus indicating a very good reliability of the acquisition system (i.e. a high coincidence of the outputs of the TRA-LOG acquisition system and of the Sigma DynaTest). The highest differences are all localized in a single PTO-speed sub-range (500-600 rpm), but, observing the plots of the two systems in the whole speed-range, we can notice a high alignment of the points of the TRA-LOG acquisition system and an anomalous lowering of the curve recorded by the Sigma DynaTest, probably due to a extemporaneous problem occurred during that test (e.g., due to a lower fuel flow rate in instants, then recovered at other speeds). The exclusion of these points results in a lowering of maximum percentage 
errors down to about $2 \%$, further rising the reliability of the acquisition system, which recordings can be considered substantially equal to the acquisitions made by the Sigma DynaTest.
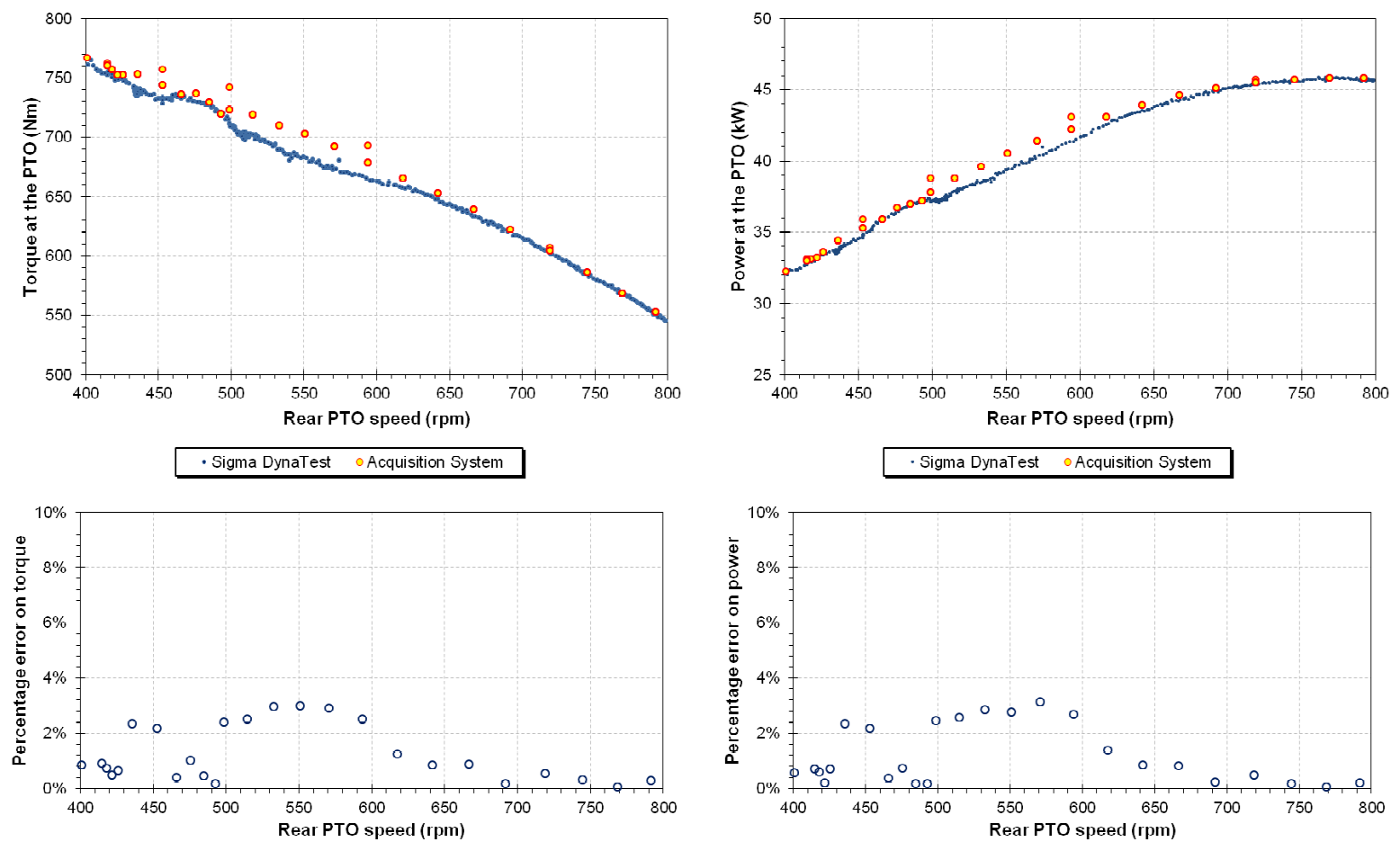

Fig. 9. Enlargements of 400-800 rpm torque (top left) and power (top right) plots at PTO of New Holland T4020V tractor, in correspondence with related error diagrams (at the bottom)

\section{Conclusions}

Starting from the need to have an acquisition system connecting many different transportable scientific instruments to test agricultural engines, a four-phase development procedure has been followed. A possible layout of this system was firstly designed. Thanks to an analysis of the relevance domain of the instruments and to a classification of the capabilities of each instrument, a hierarchicaltree architecture for this system has been chosen. At the top of this tree there is a subsystem for the coordination and control of all units, in this case a PC with proper software. Then, the hardware and software interfaces for communicating with the different units were set up (if already present) or created (if absent). In this phase, the greater effort was directed towards the trailed PTO-dyno, which did not have any physical interface to access the measured data. A change made on the control printedcircuit-board allowed the positioning of an RS-232 socket to connect this instrument to the control unit. Instead, at the software level, it was decided to coordinate the whole acquisition system through a program (named "TRA-LOG") written with the visual-programming language "G" of LabVIEW, installed on the PC chosen for the system coordination. Other than allowing the management of the signals coming from the instruments and the storing of the data in a text file, the same language allowed also easy creation of a graphical interface to control the system and display many parameters in real-time (graphical and numerical visualizations). The user interface has been developed in accordance with the good-design guidelines for software, thus resulting to be highly usable in carrying out its functions, i.e. having a high level of efficiency and effectiveness.

After having codified also the procedure of use, the whole acquisition system has been tested on a New Holland T4020V tractor with a sampling frequency of $1 \mathrm{~Hz}$, ideal for making all the instruments connected to the acquisition system operate correctly. In particular, the attention was focussed on the torque and power as a function of the engine speed. The acquisitions made with the presented system (1834 acquisitions in total) for the torque end the power differ by 3.1-3.0\% at the most $1.1-1.2 \%$ on average), if compared to those obtained from the acquisition system of the dyno (namely "Sigma DynaTest"), taken as a reference. The observed differences, however small, fall within the normal torque and power fluctuations that can be observed in the tests trials. Finally, also the absolute maximum values are very close each other: $764.7-767.1 \mathrm{Nm}$ for the torque (0.3\% difference) and 
45.9-45.8 $\mathrm{kW}$ for the power ( $0.2 \%$ difference). Even with a frequency of acquisition about ten-times lower than the frequency of the Sigma DynaTest, it is possible to conclude that the new acquisition system gives well-delineated engine characteristic curves, with absolute values very close to those given by the acquisition system of the dyno, and it is therefore fully usable.

\section{Acknowledgements}

The authors wish to thank the "Consorzio Agrario di Bolzano" (the "Farmers' cooperative of Bolzano", Italy; www.ca.bz.it/) for having put at the scholars' disposal the farm tractor used in this study within the collaboration agreement started on December 13, 2018 with the DYNOTRACTOR 2 project ("Experimental setup of an in-field test apparatus for farm tractors - 2").

\section{References}

[1] Sondors K., Birkavs A., Dukulis I., Pirs V., and Jesko Z., "Investigation in Tractor Claas Ares 557atx Operating Parameters Using Hydrotreated Vegetable Oil Fuel," Engineering for Rural Development, pp. 2014, 63-68.

[2] Vojtisek-Lom M., Pechout M., and Mazac M., "Measurement of Consumption Rates of Viscous Biofuels," Fuel, 107, 2013, pp. 448-454.

[3] Tomic M., Savin L., Micic R., Simikic M., and Furman T., "Possibility of Using Biodiesel from Sunflower Oil as an Additive for the Improvement of Lubrication Properties of Low-Sulfur Diesel Fuel," Energy, 65, 2014, pp. 101-108.

[4] Bietresato M., and Friso D., "Durability Test on an Agricultural Tractor Engine Fuelled with Pure Biodiesel (B100)," Turkish J. Agric. For., 38(2), 2014, pp. 214-223.

[5] Laurinaitis K., and Slavinskas S., "Influence of Intake Air Temperature and Exhaust Gas Recirculation on HCCI Combustion Process Using Bioethanol," Engineering for Rural Development, 2016, pp. 536-541.

[6] Bietresato M., Caligiuri C., Renzi M., and Mazzetto F., "Use of Diesel-Biodiesel-Bioethanol Blends in Farm Tractors: First Results Obtained with a Mixed Experimental-Numerical Approach," Energy Procedia, 158, 2019, pp. 965-971.

[7] Caligiuri C., Renzi M., Bietresato M., and Baratieri M., "Experimental Investigation on the Effects of Bioethanol Addition in Diesel-Biodiesel Blends on Emissions and Performances of a Micro-Cogeneration System,” Energy Convers. Manag., 185, 2019, pp. 55-65.

[8] Renzi M., Bietresato M., and Mazzetto F., "An Experimental Evaluation of the Performance of a SI Internal Combustion Engine for Agricultural Purposes Fuelled with Different Bioethanol Blends," Energy, 115, 2016, pp. 1069-1080.

[9] Bietresato M., Renzi M., Mischiatti S., and Mazzetto F., "Engine Test Stand Layout and Post Processing Tools for the Detection of Many Engine Performance Parameters," ARPN J. Eng. Appl. Sci., 11(2), 2016, pp. 1309-1316.

[10] Dittrich A., Beroun S., and Zvolsky T., "Diesel Gas Dual Engine with Liquid LPG Injection into Intake Manifold," Engineering for Rural Development, 2018, pp. 1978-1983.

[11] Scheibelmasser A., Traussnigg U., Schindin G., and Derado I., 2006, "Device Integration into Automation Systems with Configurable Device Handler," Informatics in Control, Automation and Robotics I.

[12] Mikulski M., and Wierzbicki S., "The Concept and Construction of the Engine Test Bed for Experiments with a Multi-Fuel Ci Engine Fed with CNG and Liquid Fuel as an Ignition Dose," J. KONES. Powertrain Transp., 19(3), 2015, pp. 289-296.

[13] Dukulis I., Pirs V., Jesko Z., Birkavs A., and Birzietis G., "Development of Methods for Testing Automobiles Operating on Biofuels," 8th International Scientific Conference "Engineering for Rural Development," 2009, pp. 148-155.

[14] Almaliki S., Alimardani R., and Omid M., "Fuel Consumption Models of MF285 Tractor under Various Field Conditions,” Agric. Eng. Int. CIGR J., 18(3), 2016, pp. 147-158.

[15] Ravaglioli V., Ponti F., Corti E., and Cerofolini A., "Development of a Torsiometer for On-Board Application," Energy Procedia, 101, 2016, pp. 646-653. 
[16] Osadčuks V., and Galiņ̌s A., "Modernization of a Combustion Engine Test Bench," Engineering for Rural Development, Latvia University of Life Sciences and Technologies, ed., Jelgava, Latvia, 2008, pp. 103-107.

[17] Gorski K., and Smigins R., "Impact of Ether/Ethanol and Biodiesel Blends on Combustion Process of Compression Ignition Engine," Engineering for Rural Development, 2011, pp. 260265.

[18] Skukauskaite B., Mickevicius T., and Slavinskas S., "Experimental Investigation in Diesel Fuel, Rapeseed Oil and Its Blend Combustion in off-Road Diesel Engines," Engineering for Rural Development, 2013, pp. 303-307.

[19]Labeckas G., Slavinskas S., and Vilutiene V., "Combustion, Performance and Emission Characteristics of Diesel Engine Operating on Jet Fuel Treated with Cetane Improver," Engineering for Rural Development, 2013, pp. 313-318.

[20] Emberger P., Hebecker D., Pickel P., Remmele E., and Thuneke K., "Emission Behaviour of Vegetable Oil Fuel Compatible Tractors Fuelled with Different Pure Vegetable Oils," Fuel, 167, 2016, pp. 257-270.

[21] ISO, 1994, ISO/IEC 7498-1:1994 Information Technology - Open Systems Interconnection Basic Reference Model: The Basic Model.

[22] ISO, 1996, ISO 9241-10:1996 Ergonomic Requirements for Office Work with Visual Display Terminals (VDTs) - Part 10: Dialogue Principles.

[23]ISO, 1998, ISO 9241-11:1998 Ergonomic Requirements for Office Work with Visual Display Terminals (VDTs) - Part 11: Guidance on Usability.

[24] ISO, 2011, ISO/IEC 25010:2011 Systems and Software Engineering - Systems and Software Quality Requirements and Evaluation (SQuaRE) - System and Software Quality Models.

[25] Huzayyin A. S., Bawady A. H., Rady M. A., and Dawood A., "Experimental Evaluation of Diesel Engine Performance and Emission Using Blends of Jojoba Oil and Diesel Fuel," Energy Convers. Manag., 45(13-14), 2004, pp. 2093-2112.

[26] Bietresato M., and Mazzetto F., "Ideation, Realization and Experimentation of Prototype Device for Measuring Farm Tractor Fuel Consumption during Dyno Tests," Engineering for Rural Development, 2018, pp. 362-372.

[27] "Froment SIGMA 50 Dynamometers" [Online]. Available: http://www.fromentdynamometers.com/sigma-50-dynamometers.html.

[28] "Kern Platform Scale DS" [Online]. Available: https://www.kern-sohn.com/cgibin/cosmoshop/lshop.cgi?action $=$ showdetail $\&$ wkid $=152492128620844 \& 1 \mathrm{~s}=$ en\&nochache $=1$ 524921287-20843\&rubnum $=$ produkte $197.200 \&$ artnum $=$ DS \%7C- \%7C- \%7C200.

[29] Norman D., and Draper S. W., eds., User Centered System Design - New Perspectives on Human-Computer Interaction, CRC Press, Boca Raton, Florida, Stati Uniti, 1986.

[30] Pexa M., Müller M., and Hloch S., "Dynamic Measuring of Performance Parameters for Vehicles Engines," Measurement, 111, 2017, pp. 11-17. 